HStud 26 (2012)2, 205-231

DOI: 10.1556/HStud.26.2012.2.3

\title{
MELANCHTHON ODER STURM? KONKURRIERENDE SCHULMODELLE BEI DEN PROTESTANTEN IN UNGARN UND SIEBENBÜRGEN IM 16. JAHRHUNDERT UND IN DEN ERSTEN JAHRZEHNTEN DES 17. JAHRHUNDERTS
}

\author{
MÁRTA FATA \\ Institute für donauschwäbische Geschichte und Landeskunde \\ Tübingen, Deutschland
}

\begin{abstract}
Die am Anfang des 16. Jahrhunderts im Sinne des Humanismus modernisierten Lateinschulen haben sich auch in Ungarn und Siebenbürgen infolge der Reformation inhaltlich und damit strukturell weiterentwickelt. In der zweiten Hälfte des Jahrhunderts boten die frequentierten Schulen bereits ein Lehrprogramm an, das über das Trivium weit hinausging. Doch während die Schulen der Lutheraner ihr Lehrangebot mit Fächern des Quadriviums erweiterten und zunächst keine akademische Ausbildung in Theologie angeboten haben, fand in den Schulen der Reformierten eine Erweiterung des Lehrangebots mit der Einführung einer akademischen Ausbildung in Theologie und Philosophie statt. Ein weiteres Spezifikum der Schulentwicklung im Donau- und Karpatenraum war, dass im ganzen 16. Jahrhundert Melanchthons Bildungsideal bestimmend war. Sturm konnte im 16. Jahrhundert mit dem praeceptor Germaniae nicht wetteifern, weil sein aufwendiges gymnasium illustre unter den wesentlich bescheideneren Verhältnissen im Königreich Ungarn und im Fürstentum Siebenbürgen nicht als Vorbild dienen konnte. Allerdings war der Unterschied zwischen der protestantischen Gelehrtenschule Melanchthon'scher und Sturm'scher Prägung nicht gravierend. So konnten gerade außerhalb der deutschsprachigen $\mathrm{Ge}-$ biete beide Modelle harmonisierend miteinander verbunden werden.
\end{abstract}

Schlagwörter: Reformation, Bildungswesen, Schulmodelle, Sturm, Melanchthon, Ungarn, Siebenbürgen

\section{Die Voraussetzungen}

Die Reformation hatte nach der Schlacht bei Mohács im Jahre 1526 im dreigeteilten Königreich Ungarn Fuß gefasst. In dem habsburgisch gewordenen Teil Ungarns verbreitete sich die helvetische Reformation vor allem bei den Adligen in den von Wien entfernt liegenden nordostungarischen Gebieten und in den mehrheitlich von Ungarn bewohnten Marktflecken und Dörfern, während Adlige in Westungarn und das deutsche Bürgertum - beide vor allem aus pragmatischen Überlegungen - größtenteils beim Luthertum verblieben. Im osmanisch besetzten 
Zentralungarn und im Fürstentum Siebenbürgen, das sich im Laufe des 16. Jahrhunderts im Osten des Landes etablierte, nahmen die Siebenbürger Sachsen geschlossen die lutherische Reformation, die Ungarn dagegen mehrheitlich die calvinische Richtung an. ${ }^{1}$

Der Weg zur lutherischen wie auch zur reformierten Theologie im Donau- und Karpatenraum wies im europäischen Vergleich einige Besonderheiten auf. So spielte bei der Verbreitung der Reformation neben Luther sein Mitstreiter Philipp Melanchthon eine bestimmende Rolle, der durch seine zahlreichen Studenten aus Ungarn und Siebenbürgen eine viel intensivere Beziehung zum Donau- und Karpatenraum unterhielt als Luther. Den Zugang zur Schweizer Reformation fanden die ungarischen Protestanten wiederum durch die von Wittenberg ausgehenden Impulse, wobei die Verbreitung und Durchsetzung der helvetischen Reformation - ohne Calvins persönliche Anteilnahme - vorwiegend durch die Rezeption seiner Werke erfolgte. ${ }^{2}$

Das Todesjahr Melanchthons 1560 stellte in der Geschichte der ungarischen Reformation eine wichtige Zäsur dar. Der ungarische Coetus, die studentische Vereinigung an der Wittenberger Universität für Finanzierungs-, Disziplinar- und andere Angelegenheiten, die 1555 trotz eines generellen Verbots der Gründung von Studentennationen in Wittenberg gerade mit Melanchthons Hilfe zustande gekommen war, wurde konfessionell und somit auch ethnisch homogen, weil ihr lutherische Ungarländer nicht mehr beitraten. Die ungarischen Coetus-Mitglieder pflegten von nun an mit jenen Professoren engen Kontakt, die Melanchthons Erbe des Dialogs der reformatorischen Richtungen bewahrten oder selbst zur helvetischen Richtung neigten und mit den Schweizer Theologen in Verbindung standen wie Melanchthons Schwiegersohn Kaspar Peucer.

Mit Peucers Empfehlungsschreiben haben im Jahre 1566 Mátyás Túri und Bálint Szikszai Hellopaeus den Rektor der Genfer Akademie Théodore de Bèze aufgesucht und ließen sich dort am 14. Oktober als erste aus Ungarn stammende Studenten immatrikulieren. ${ }^{3}$ Wesentlich mehr ungarische Studenten sollten im 16. Jahrhundert diesen beiden an die von Calvin gegründete Akademie nicht folgen - insgesamt ließen sich nachweislich nur fünf inskribieren und zwölf besuchten die Bildungsanstalt als Gasthörer -, weil das teuere Leben in Genf für die zumeist armen peregrini aus Ungarn und Siebenbürgen unerschwinglich blieb. ${ }^{4}$

Einige von ihnen kehrten allerdings mehrmals nach Genf zurück, wie etwa Túri. Dieser wirkte zwischen 1572 und 1575 als Rektor am Debrecener Reformierten Kollegium, so kamen seine mehrmaligen Gespräche mit Bèze sicherlich auch dem Unterricht am Kollegium zugute. ${ }^{5}$ Allerdings konnte Túri in Genf die Variante einer Hohen Schule kennen lernen, welche die Konzepte der Lausanner und der Straßburger Schule miteinander verband. Denn durch den Exodus von vier Lausanner Professoren unter der Leitung von Bèze nach Genf erfolgte auch der Transfer der Schulorganisation, während Calvin, der zwischen 1538 und 1541 
im Straßburger gymnasium illustre theologische Vorlesungen hielt, dort das Unterrichtsmodell von Johannes Sturm schätzen lernte und bei der Gründung der Genfer Akademie 1559 dessen Rat einholte. ${ }^{6}$ Schon dieses einzelne Beispiel, dass ein peregrinus aus Ungarn und späterer Professor zunächst in Wittenberg Melanchthons pädagogische Leitsätze, dann in Genf ein grundlegend in Straßburg entwickeltes Schulmodell kennen lernen konnte, zeugt von der Vielfalt und zugleich von den Umwegen der Einflussmöglichkeiten bei der Formierung des protestantischen Schulwesens, die im 16. Jahrhundert nicht nur für den Donau- und Karpatenraum charakteristisch waren.

\section{Protestantische Schulmodelle in der ersten Hälfte des 16. Jahrhunderts und ihre Bedeutung für den Donau- und Karpatenraum}

Die Forderung nach Gründung von höheren Schulen im Sinne der studia humanitatis, welche die Humanisten schon seit dem 15. Jahrhundert erhoben hatten, erschien mit der Verbreitung der Reformation im ersten Drittel des 16. Jahrhunderts dringlicher als je zuvor. Denn der neue Glaube bedurfte einerseits der unterrichtenden Prediger, andererseits der im Evangelium gebildeten Laien. Schon in seiner Antrittsvorlesung an der Wittenberger Universität im Jahre 1518 erklärte Melanchthon, dass evangelische Frömmigkeit ohne Bildung nicht denkbar sei. ${ }^{7}$ Das an der im Sinne der Glaubenserneuerung reformierten Wittenberger Universität eingeführte Lehrmodell der lectio publica und die damit einhergehende Auslagerung des propädeutischen Unterrichts aus der Universität werteten die humanistischen Lateinschulen auf, wo die soliden Grundlagen der lateinischen Sprache als Voraussetzung eines erfolgreichen Universitätsbesuchs vermittelt werden sollten. Doch diese Schulen waren im frühen 16. Jahrhundert nicht flächendeckend vorhanden, zudem hatte die Einführung der Reformation das alte Schulwesen mit seinen Kloster- und Pfarrschulen weitgehend zerrüttet. ${ }^{8}$ So war es nicht weiter verwunderlich, dass Melanchthon, der bei der Visitation der sächsischen Schulen in den Jahren 1527/1528 diese Probleme erkannt hatte, die Aufwertung der Lateinschulen empfohlen hatte. ${ }^{9}$ Bei den von Melanchthon besuchten Lateinschulen handelte es sich dem Typus nach um so genannte Trivialschulen, deren Bezeichnung sich von dem an diesen Schulen gelehrten Trivium - bestehend aus den elementaren drei der sieben freien Künste - ableitete.

In der städtischen Lateinschule begann die Reformierung des Unterrichts unter dem Einfluss des Humanismus schon vor der Reformation, indem etwa anstelle von scholastischen Werken antike und humanistische Autoren im Lektürekanon und das Griechische als neues Unterrichtsfach eingeführt wurden. Organisatorisch waren die Schüler nicht nach Schuljahren oder -alter, sondern entsprechend ihrer Leistungen in drei Stufen, Lehrgangsklassen, eingeteilt. In Anbetracht der 
trostlosen Lage der Schulen in Kursachsen, wo sich die Städte zumeist nur einräumige Schulen und wenig Lehrpersonal leisten konnten, sah Melanchthon weiterhin das System der drei „Haufen“ vor, bei dem in der Elementarstufe neben einer religiösen Grundbildung Lesen, Schreiben und Rechnen und in der Mittelstufe lateinischer Grammatikunterricht erteilt wurden, während in der dritten Stufe die reiferen Schüler Dialektik und Rhetorik lernten. Die am schnellsten ersichtliche Neuerung bedeutete die von Melanchthon empfohlene inhaltliche Reduzierung und Straffung der bis dahin verwendeten Lehrbücher der Scholastik, um den Schülern die zu vermittelnden Inhalte in knapper und präziser Weise beibringen zu können. Aus diesem Grund sollten weder Griechisch noch Hebräisch auf dem Lehrplan stehen. ${ }^{10}$

Melanchthons Leitsätze für die Einrichtung der Lateinschulen konnten auch für die protestantischen Schulträger und Schulmänner in Ungarn und Siebenbürgen, die nach 1526 mit viel größeren finanziellen Problemen zu kämpfen hatten als die Schulen in Kursachsen, wegweisend sein. Allerdings bestand Melanchthons hervorragende Bedeutung für die Schulträger und Schulmänner in Ungarn und Siebenbürgen in seinem humanistischen Bildungsideal, das stärker die aristotelische Wissenschaftssystematik wahrte und einen fachlich breiter angelegten Polyhistorismus pflegte als etwa das von Sturm. ${ }^{11}$ Die Verbindung einer nicht auf dogmatische Kontroversen abzielenden Theologie mit humanistischer Gelehrsamkeit und der besonderen Pflege von Ethik, Poetik, Rhetorik und Geschichte waren jene Prinzipien des Melanchthon'schen Bildungskonzepts, die für die Protestanten im Donau- und Karpatenraum während des 16. Jahrhunderts als Modell fungieren konnten. Denn anders als im Heiligen Römischen Reich deutscher Nation gingen sowohl die Reformation als auch die Herausbildung der konfessionellen Kirchen ohne bewaffnete Auseinandersetzungen vonstatten.

Auch wenn Melanchthons Bildungsideal und pädagogisches Konzept von der überlegenen Wirkmächtigkeit der Wittenberger Reformation in den deutschsprachigen und ostmitteleuropäischen Ländern profitieren konnte, waren seine Vorstellungen nicht die einzigen. Denn während der praeceptor Germaniae für Kursachsen mit einer florierenden Universität - nach 1547 sogar mit zwei protestantischen Universitäten - den flächendeckenden Ausbau der Trivialschulen mit drei Lehrgangsklassen empfehlen konnte, entwickelten universitätslose protestantische Territorien andere Modelle. So entstand im oberdeutsch-schweizerischen Raum ein neuer Schultypus, das humanistische gymnasium illustre. Diese höhere Schule ohne Universitätsabschluss kombinierte die schola classica mit der sich daran anschließenden schola publica, in welcher eine propädeutische Lehre in den höheren Fakultätsdisziplinen Theologie, Jurisprudenz und Medizin angeboten wurde. ${ }^{12}$

Als Orientierungsmuster für die meisten akademischen Gymnasien im Heiligen Römischen Reich deutscher Nation diente die 1538 nach den Plänen von 
Johannes Sturm gegründete Straßburger Schule, bestehend aus einer zuerst neun-, dann zehnjährigen schola classica (Gymnasium) und einer daran anschließenden vierjährigen schola publica (Akademie). In Sturms Gymnasium, dem wiederum die Lütticher Schule der Hieronymianer Vorbild war, gab es Jahrgangsklassen mit jährlichen Versetzungsprüfungen, außerdem ein System der klassengebundenen Lehrer. Sturms pädagogisches Konzept zielte darauf ab, den Schülern eine äußere und innere Ordnung zu vermitteln. Die äußere Ordnung sollte durch den gleichmäßig geregelten Tagesablauf und die Hierarchie in der Schule erreicht werden. Die Schüler der einzelnen Klassen waren in Decurien eingeteilt, an deren Spitze jeweils ein gewählter Decurio stand, der dem Klassenlehrer etwa in Disziplinarfragen behilflich war. Der Weg zur inneren Ordnung, das heißt zum klar strukturierten Denken, sollte wiederum über die Förderung der Beredsamkeit führen. Das in der Formel sapiens atque eloquens pietas zum Ausdruck gebrachte Bildungsideal Sturms legte den Akzent eindeutig auf die eloquentia, die stark auf Ciceros Werke ausgerichtete Rhetorik. ${ }^{13}$

Sturms besondere Bedeutung für den Schulunterricht in Ungarn und Siebenbürgen bestand in der klassischen rhetorischen Bildung. Die dabei hervorgehobene Stellung der lateinischen Sprache konnte im Gebiet des Stephansreichs schon deshalb auf großen Widerhall stoßen, weil Latein nicht nur die Sprache von Kirche und Wissenschaft, sondern zugleich die offizielle Amts- und praktische Verkehrssprache der Organe der Stände und der Verwaltung im Stephansreich war und bis ins 19. Jahrhundert blieb.

Zwischen der Lateinschule und dem gymnasium illustre entstand eine breite Palette an örtlichen und regionalen Varianten von Schulen, welche sich als Vorbereitungsanstalten für ein Universitätsstudium definieren wollten und konnten. Eine dieser Bildungsanstalten war die von Arno Seifert als quasi-illustre Gymnasium bezeichnete Schule von Valentin Trotzendorf im schlesischen Goldberg. Der Melanchthon-Schüler aus Schlesien baute die von ihm zwischen 1531 und 1556 geleitete Trivialschule von Goldberg im Herzogtum Liegnitz in eine Bildungsanstalt mit sechs Lehrgangsklassen aus. Für die reiferen Schüler wurden neben Dialektik und Rhetorik auch Bereiche des Quadriviums wie Arithmetik, Astronomie und Naturphilosophie gelehrt. ${ }^{14}$ Das anspruchsvolle Lehrpensum, das zunächst mit einem Lehrer gemeistert wurde, erforderte mit der Zeit nicht nur die Anstellung von einem weiteren Lehrer und zwei Praeceptoren, sondern auch die konsequente Heranziehung der reifen Schüler für den Unterricht der unteren Klassen. Dem effektiven Unterricht sollten auch die von Trotzendorf ausgearbeiteten Schulgesetze dienen, die auf eine strenge Disziplin und verstärkte Selbstverwaltung abzielten. Aus der Reihe der Schüler, die ungeachtet ihrer ständischen und sozialen Herkunft in der Schule gleichgestellt waren, wurden nach dem Muster der römischen Republik Würdenträger ernannt, die über Ordnung und Sauberkeit in Schule und Internat sowie über die Arbeit und Aufgaben der 
Mitschüler wachten. Über dem ganzen Schulstaat stand Trotzendorf als dictator perpetuus. $^{15}$

Der ungarischen Schulgeschichtsforschung ist es bisher noch nicht gelungen, die Bedeutung des Trotzendorf'schen Systems im Detail zu klären. Doch es zeichnet sich auch ohne neuere Forschungsergebnisse ab, dass dieses Schulmodell gerade in Gebieten mit wenig ausgebildeten Lehrern und begrenzten finanziellen Möglichkeiten, zu denen auch das dreigeteilte Ungarn gehörte, erfolgreich zum Vorbild dienen konnte. Denn die Goldberger Schule mit ihrer strengen Ordnung konnte auch mit wenigen Lehrern der Vorbereitung auf die höheren Fakultäten der Universität dienen.

\section{Probleme der Schulforschung in Ungarn und Siebenbürgen}

Die ungarische Schulgeschichtsschreibung ist sich in der Bewertung der Auswirkung der Reformation auf das ungarische Unterrichtssystem nicht einig. Wie die Budapester Schulhistorikerin Erika Kopp in ihrem vor kurzem veröffentlichten Beitrag zu Calvins Wirkung auf das ungarische Unterrichtswesen feststellte, wird nach wie vor die Frage diskutiert, wie tief greifend sich die Reformation auf das ungarische Schulwesen im 16. Jahrhundert ausgewirkt hat. ${ }^{16}$

Luthers Programm der muttersprachlichen Kleinschulen wurde auch in Ungarn und Siebenbürgen aufgegriffen. ${ }^{17}$ Doch die Hauptaufmerksamkeit widmete man den humanistischen Lateinschulen, in denen die neue konfessionelle Elite herangezogen werden sollte. ${ }^{18}$ Nachdem es in Siebenbürgen und in Ungarn bis 1581 beziehungsweise bis 1635 keine Universitäten gab, kam diesem Bildungsmodell eine besondere Bedeutung zu. Die Meinungen in der ungarischen Forschung gehen allerdings darüber auseinander, inwieweit die Reformation im dreigeteilten Ungarn im 16. Jahrhundert einen neuen Schultypus mit neuen Lehrplänen und Methoden hervorbrachte. Während vor allem ältere ungarische Autoren der Ansicht waren, dass um die Mitte des 16. Jahrhunderts auch in Ungarn und Siebenbürgen ein neuer, evangelischer Schultypus entstand, ${ }^{19}$ betont der Doyen der ungarischen Schulgeschichtsforschung, István Mészáros, das Fortleben der im Sinne der studia humanitatis schon um 1500 modernisierten und von den Magistraten übernommenen städtischen Pfarrschulen unter protestantischer Leitung. Diese Schulen folgten nach Mészáros sowohl in ihrem organisatorischen Aufbau als auch mit ihrem Lehrstoff dem zur Zeit der Renaissance entstandenen Modell der Trivialschulen - wenn auch anders als im Humanismus die Schule der Reformation nicht mehr das Lehren und Lernen der Vollendung des Menschen, sondern des Glaubenskönnens in den Mittelpunkt stellte. ${ }^{20}$

Anlass zur Debatte über die Schulen gibt nach wie vor die schlechte Quellenlage. Insgesamt wird die ungarische und siebenbürgische Schulgeschichtsfor- 
schung dadurch erschwert, dass für das 16. Jahrhundert nicht nur keine systematischen und kritischen Quelleneditionen, sondern überhaupt wenig Quellen vorliegen. Oft fehlen Informationen über die Gründung der Schulen, ihr Lehrpersonal und ihre Lehrinhalte, nicht zuletzt weil in den meisten Schulen Zahl und Stoff der zu lehrenden Fächer nicht genau vorgeschrieben waren. Die fehlenden Angaben erschweren auch die Bestimmung der Struktur der Schulen. Die bis heute bekannten Dokumente untermauern jedenfalls nicht eindeutig Mészáros' Meinung, wonach im dreigeteilten Ungarn bis zum ausgehenden 16. Jahrhundert bei allen Konfessionen dem Typus nach Trivialschulen charakteristisch waren. ${ }^{21}$ Dies wird auch von den zeitgenössischen Quellen über die Schulstrukturen nicht bestätigt.

Imre Újfalvi, ${ }^{22}$ Professor für Mathematik und Hebräisch und zwischen 1596 und 1599 Rektor des Debrecener Reformierten Kollegiums, bezeichnete in seiner 1597 verfassten Studienanleitung alle Schulen im Ungarn des 16. Jahrhunderts gegenüber den scholae maiores (Universitäten und Hohen Schulen) als scholae minores, wobei er zwischen den scholae triviales und den scholae illustres - auch Partikularschule genannt - unterschied. ${ }^{23}$ Während er mit scholae triviales die kleinen Schulen mit zwei Stufen und einem Lehrer bezeichnete, verstand er unter scholae illustres die dreistufigen Schulen, wo mindestens zwei erwachsene Lehrer tätig waren. In keiner der ungarischen und siebenbürgischen Bildungsanstalten wurde also nach Sturms Modell in Jahrgangsklassen, sondern weiterhin auf traditioneller Art nach Lernstufen unterrichtet. Diese Tatsache begründete Újfalvi damit, dass die niedrige Zahl der Lehrer und die Zweckmäßigkeit des Unterrichts die Beibehaltung des alten Systems erforderten. ${ }^{24}$ Die schola illustris oder Partikularschule konnte also mit zahlenmäßig wenigen Lehrern und mit geringem Aufwand am besten der Etablierung einer konfessionellen Elite dienen. ${ }^{25}$ Doch wie waren diese scholae illustres strukturiert? Und was haben sie angeboten?

\section{Konkurrierende Einflussnahmen - eigenständige Lösungen?}

Durch die Verbindung der Reformation mit der Rezeption humanistischer Ideen gewann das Unterrichts- und Bildungswesen auch in Ungarn und Siebenbürgen eine neue Dimension. Bereits in den 1530er Jahren - das zeigen zahlreiche Beispiele - wurde Melanchthons pädagogisches Konzept unter den spezifischen Voraussetzungen im Donau- und Karpatenraum in die Praxis umgesetzt.

Im oberungarischen Bartfeld gehörte der Stadtpfarrer und Schulmann Valentin Stöckel (1510-1560) zu den treuen Melanchthon-Schülern. ${ }^{26}$ Der Unterricht in der Bartfelder Schule wurde schon zwischen 1516 und 1522 durch den Humanisten Valentin Eck aus Lindau am Bodensee im Sinne des pädagogischen Programms des Elsässer Humanisten Jakob Wimpfeling umgestaltet. ${ }^{27}$ Stöckel, selbst Absolvent der Eck'schen Schule, setzte seine Studien beim englischen 
Humanisten Leonhard Cox an der Schule in Kaschau, dann an der Universität Wittenberg fort. Dort pflegte Stöckel zu Melanchthon ein besonders inniges Verhältnis, weshalb er durch Vermittlung seines akademischen Lehrers eine Stelle in der gerade durch diesen reformierten Schule im mansfeldischen Eisleben bekam. Die für die Eislebener Schule ausgearbeitete Schulordnung ist als ein Vorläufer des von Melanchthon verfassten kursächsischen Lehrplans anzusehen und stimmt mit demselben in allen wesentlichen Punkten überein.

Die Bildungsanstalt von Eisleben und Melanchthons Ausführungen in seiner kursächsischen Visitation dienten Stöckel bei der Einrichtung der Bartfelder Schule mit Sicherheit als Orientierungsmuster. Denn in seiner Schulordnung von $1540^{28}$ - welche die früheste bekannte Ordnung einer evangelischen Schule im Donau- und Karpatenraum darstellt - stand die Einheit der humanistischen pädagogischen Praxis und des reformatorischen Glaubens ganz im Sinne des Melanchthon'schen Bildungsideals prudentia et eloquentia im Mittelpunkt.

Die Schule von Bartfeld gehörte zu den Lateinschulen mit einem Lehrer sowie mit Aushilfelehrern aus der Reihe der reifen Schüler. Der Unterricht erfolgte in drei Lehrgangsklassen, wobei in der höchsten Stufe außer Rhetorik und Dialektik auch Arithmetik und Philosophie unterrichtet wurden. Für die reifen Schüler richtete Stöckel auch ein colloqium litterarum ein, das in Form von Disputationen abzuhalten war, wo sich die Schüler wahlweise mit Themen wie Philosophie, Physik, Ethik und Theologie auseinandersetzen sollten. ${ }^{29}$ Demnach hatte Stöckel ausgewählte Schüler, darunter auch zahlreiche Söhne von Adelsfamilien, in die Grundlagen des Quadriviums eingeführt. Großen Wert legte er auch auf die Fortführung der Bartfelder Tradition der Schultheateraufführungen, obwohl Melanchthon das Schultheater ablehnte. Die evangelische Kirchensynode von Eperiesch bestätigte im November 1546 Stöckels Schulordnung, wodurch diese von einer Vielzahl von Schulen in der Zips und in Oberungarn übernommen wurde. Bald wurde die Bartfelder Schule aus ganz Ungarn und Siebenbürgen und sogar aus Schlesien und Polen besucht und erfüllte somit eine überlokale Funktion. ${ }^{30}$

In der siebenbürgischen königlichen Freistadt Kronstadt orientierte sich der Reformator Johannes Honterus (1498-1549) bei der Einrichtung der Schule ebenfalls an Melanchthon, allerdings mehr an dessen für die „Obere Schule“ Sankt Ägidien der Reichsstadt Nürnberg ausgearbeitetem Modell. Honterus, der sich nach einem Studium in Wien und Krakau in den 1520er Jahren in Nürnberg aufhielt, konnte dort die Pläne des von Melanchthon für Nürnberg konzipierten neuen Typus der protestantischen Gelehrtenschule kennen lernen, der einer Artistenfakultät nahe kam. Das Fächerspektrum der Scholae Coronensis umfasste das Trivium und Bereiche des Quadriviums wie Geographie gepaart mit Arithmetik und Astronomie, Verslehre und Musik. Neben dem Schulrektor Honterus unterrichtete ab 1543 auch ein Lektor die reiferen Schüler, wobei für den Unterricht in den unteren Stufen nicht nur ältere Schüler, sondern auch der Kantor der Stadtpfarr- 
kirche für den Musikunterricht und der Sekretär des Stadtmagistrats für den Unterricht in Schreiben, Rechnen und Arithmetik eingesetzt wurden. ${ }^{31}$

Für die innere Ordnung der Kronstädter Schule dienten wiederum die Schulgesetze des Rektors der Nürnberger Sebaldschule, Sebald Heyden, die von Honterus fast wortwörtlich übernommen wurden. ${ }^{32}$ Honterus' Schulstaat war in seinen Grundsätzen zwar deutlich an die res publica der Goldberger Schule angelehnt, durch die Wahl der Würdenträger jedoch wesentlich demokratischer gestaltet als die Schule von Trotzendorf, für die erst 1546 eine gedruckte Ordnung erschien. ${ }^{33}$ Deshalb haben ältere Autoren vermutet, dass Honterus bei der Organisation des coetus das Straßburger Modell Sturms zum Vorbild nahm, ${ }^{34}$ was allerdings nicht zu belegen ist. Die 1542 von Honterus verfasste Kirchenordnung, die auch die Schulordnung beinhaltete, wurde 1547 in wenig veränderter Form vom Selbstverwaltungsorgan der Siebenbürger Sachsen, der „Nationsuniversität“, als verpflichtend eingeführt, wodurch die Kronstädter Schule ihre regionale Bedeutung entfalten konnte. ${ }^{35}$

Im Laufe des 16. Jahrhunderts entwickelten sich die frequentierten Schulen in den königlichen Freistädten - so nachweislich im oberungarischen Neusohl und Leutschau oder im siebenbürgischen Klausenburg und Hermannstadt - auch strukturell weiter, indem sie ihren Unterrichtsstoff genau definierten, ihre Lehrfächer mit Bereichen des Quadriviums erweiterten und dementsprechend die drei Lehrstufen mit Einführung von mehreren Lehrgangsklassen ausdifferenzierten. ${ }^{36}$ In den 1560er Jahren gab es sowohl in Neusohl als auch in Leutschau bereits acht Klassen. Ihrem Typus nach waren diese Schulen schon mehr oder weniger vollwertige Gymnasien ohne lectiones publicae. Auch wenn Sturms gymnasium illustre sicherlich den Schulmännern in Ungarn und Siebenbürgen als nachahmungswürdig erschien, waren sie doch gezwungen, die Schulen den im Donau- und Karpatenraum vorherrschenden zerrütteten politischen Verhältnissen und vor allem ihren beschränkten finanziellen Möglichkeiten anzupassen. In inhaltlicher Hinsicht zeigten sich die Bildungsanstalten allerdings sehr offen und sie übernahmen etwa die in Mittel- und Westeuropa allgemein verbreiteten Lehrbücher. In der Schulordnung der Neusohler Schule beispielsweise - die 1574 von dem aus Straßburg stammenden Rektor Abraham Schremmel, der höchstwahrscheinlich auch in Straßburg studiert hatte, schriftlich niedergelegt wurde - waren Schulbücher etwa von Nicolaus Clenardus, Gemma Frisius, Sebald Heyden, Melanchthon, Nicolaus Medler und Sturm vorgeschrieben. ${ }^{37}$

Anders als die lutherischen Schulzentren haben die frequentierten reformierten Schulen - erst seit dem Ende des 17. Jahrhunderts als Kollegien bezeichnet - wie Sárospatak, Pápa, Debrecen oder Klausenburg im Zuge der Verbreitung der helvetischen Reformation ab der zweiten Hälfte des 16. Jahrhunderts ihr Lehrangebot nicht nur in Richtung Quadrivium, sondern mit einer philosophischen und theologischen Ausbildung in Form von öffentlichen Vorlesungen weiterentwi- 
ckelt. ${ }^{38}$ Die akademische Ausbildung umfasste häufig nur Theologie, wobei im Fall der am meisten frequentierten Anstalten sowohl Philosophie als auch Theologie gelesen wurden. Auch Griechisch und Hebräisch wurden eingeführt, ${ }^{39}$ wobei erstere Sprache - ganz im Sinne von Melanchthon und Sturm - als Bestandteil der humanistischen Ausbildung galt, während letztere fakultativ und nur für die Predigerkandidaten vorgeschrieben wurde. An den großen reformierten Schulen erhielten die Schüler somit eine abgeschlossene Ausbildung, auch wenn die Bildungsanstalten keine akademischen Grade erteilten, weshalb auch Reformierte einen Universitätsabschluss im Ausland erwerben mussten.

Der Struktur nach zeigten die großen Kollegien mit den Schweizer reformierten Hohen Schulen eine Ähnlichkeit, ${ }^{40}$ wobei, wie Ùjfalvi schrieb, in Ungarn und Siebenbürgen zunächst das alte System der Lehrgangklassen beibehalten wurde. Der Unterricht in der elementaren, gymnasialen und akademischen Stufe fand im gleichen Gebäude ohne institutionelle Trennung statt, nicht zuletzt deshalb, weil die reifen oder absolvierten Studenten vom rector und conrector konsequent als Hilfslehrer eingesetzt wurden. Um die frequentierten Schulen, die „Mutterkollegien", gruppierten sich kleinere und kleinste Schulen in den Marktflecken und Dörfern, in denen Absolventen des Kollegiums als Lehrer oder Praeceptoren tätig waren. Viele von ihnen übten sich an den „Partikularschulen“ der Kollegien im Lehrerhandwerk, bevor sie sich mit dem dort verdienten Geld auf die Peregrination ins Ausland begaben oder eine Anstellung als Prediger oder Schulmeister erhielten. ${ }^{41}$ Dieser reformierte Schultypus wies mehrere Varianten auf, so konnte beispielsweise an einigen der kleineren Schulen die theologische Ausbildung gleich nach der zweiten Stufe, also dem lateinischen Grammatikunterricht, erfolgen.

Welches Vorbild dieses Modell hatte, ist auf der Grundlage des heutigen Wissensstands nicht eindeutig zu entscheiden. Mészáros nimmt den Standpunkt ein, dass die katholischen Domkapitelschulen des Mittelalters den reformierten Kollegien als Muster dienten. Da sich das System jedoch erst in der zweiten Hälfte des 16. Jahrhunderts allmählich etablierte, waren wahrscheinlich die Schulkollegien der Jesuiten - die seit 1586 auch überall in Ungarn gegründet wurden und die über einen Pastoralkurs verfügten, somit also eine abgeschlossene Ausbildung ermöglichten - für die Weiterentwicklung der reformierten Kollegien ausschlaggebend. ${ }^{42}$ Allerdings haben mit Sicherheit ebenso die Schweizer Hohen Schulen eine gewisse Vorbildfunktion erfüllt, auch wenn beim heutigen Stand der Forschung weder der jesuitische noch der schweizerische Einfluss eindeutig nachzuweisen ist. 


\section{Versuche zur Gründung von Akademien im Ungarn und Siebenbürgen des 16. Jahrhunderts}

Haben die Schulen der Reformierten mit einer Form der quasi Hohen Schule den Schultypus gefunden, der den Bedarf an calvinistischen Dorfpredigern und Schulmeistern schnell decken konnte, so unternahmen die Lutheraner schon im 16. Jahrhundert mehrere Versuche, eigene Hohe Schulen zu gründen.

Im Königreich Ungarn war der ungarische König und römisch-deutsche Kaiser Maximilian II., der eine protestantenfreundliche Haltung einnahm, der Initiator. Er förderte nicht nur Sturms Straßburger Gymnasium mit der Privilegierung durch die niederen Graduierungsrechte 1566, sondern unterstützte auch die Schulen der ungarischen Protestanten. 1571 holte er die Meinung der Ungarischen Kammer zum Ausbau einer der oberungarischen lutherischen Schulen zur Akademie ein, wobei er selbst anscheinend die Schule in der königlichen Freistadt Leutschau präferierte. In ihrem Gutachten schlugen die königlichen Räte eine stufenweise Erweiterung der dortigen Schule vor, indem zunächst vier Professoren aus dem Heiligen Römischen Reich deutscher Nation (,,professores artium ac theologiae ex Germania“) für den Unterricht der Fächer Theologie, Logik, Rhetorik und Grammatik angestellt werden sollten. ${ }^{43}$ Der Plan konnte wegen Maximilians Tod zwar nicht umgesetzt werden, doch inzwischen hatten die Leutschauer Bürger den Plan anscheinend selbst aufgegriffen, denn Maximilians Nachfolger, Rudolf II., untersagte aus konfessionspolitischen Gründen dem Stadtmagistrat am 31. Dezember 1588 das ehrgeizige Vorhaben zur Gründung einer Hohen Schule. ${ }^{44}$ Das Ziel der ungarischen Evangelisch-Lutherischen konnte erst 1667 in der königlichen Freistadt Eperiesch mit Hilfe der evangelischen Stände und mit der Unterstützung aus dem protestantischen Ausland realisiert werden.

Im Verwaltungs- und Handelszentrum der Siebenbürger Sachsen, Hermannstadt, plante 1549 die „Nationsuniversität“ eine höhere Schule für die gesamte siebenbürgisch-sächsische natio zu eröffnen und holte dazu die Meinung des sich in Klausenburg aufhaltenden italienischen Gelehrten Francesco Stancaro ein. Dieser schlug ein Partikulargymnasium mit fünf Professoren für Theologie, Hebräisch, Griechisch, Latein und für Rhetorik und Dialektik vor. Auch wenn der ehrgeizige Plan nicht in der ursprünglichen Form verwirklicht werden konnte, wurde die Schule allmählich etwa durch Anstellung von zwei Lektoren zu einem vollwertigen Gymnasium ausgebaut.

1578 nahm der höchste Würdenträger der siebenbürgisch-sächsischen natio, der Königsrichter Albert Huet, erneut den Plan zur Errichtung einer Akademie auf. Huet, selbst ein Absolvent der Wiener Universität, wollte die Hermannstädter Schule zur gemeinsamen Akademie der Siebenbürger Sachsen ausbauen und dazu Lehrer aus dem römisch-deutschen Reich einladen. ${ }^{45}$ Doch das Vorhaben, die Schule als eine landständische Akademie einzurichten, deren Kosten von der 
„Nationsuniversität“ getragen werden sollten, stieß diesmal auf eine geteilte Meinung der siebenbürgisch-sächsischen Verwaltungsbezirke, von denen manche die Schulzentren Kronstadt im Burzenland und Bistritz im Nösnerland unterstützen wollten.

Huet ließ auch ohne die einvernehmliche Unterstützung eine äußere und innere Reformierung in der Schule einleiten. Das alte Schulgebäude wurde renoviert und erweitert, der Lehrplan durch die Stärkung der Rolle der Rhetorikausbildung unter der Leitung des 1591 zum Rektor gewählten Georg Dietrich modernisiert. Dietrich studierte 1587 in Straßburg und erwarb dort den Magistergrad. ${ }^{46} \mathrm{Ihm}$ war es zu verdanken, dass neben der evangelischen Frömmigkeit die Beredsamkeit zum erstrangigen Ziel erhoben wurde. 1598 erhielt die Schule auch eine neue Schulordnung, ausgearbeitet vom Rektor Leonhard Hermann, der in Frankfurt an der Oder studiert hatte. Nach dem siebenbürgisch-sächsischen Bischof Friedrich Teutsch, der im 19. Jahrhundert den siebenbürgischen Schulen zahlreiche Aufsätze widmete, kamen in dieser Schulordnung Trotzendorfs und Sturms Einflüsse zur Geltung. ${ }^{47}$

Schon die beiden Beispiele zeigen, dass die Gründung von Hohen Schulen ohne den fürstlichen oder ständisch-korporativen Willen nicht möglich war. Aber selbst dieser reichte in einer Region, wo der politische und konfessionelle Status quo durch äußere Umstände stets bedroht war, nicht immer aus. Sind Pläne einer Akademiegründung des siebenbürgischen Fürsten Johann Sigismund wegen seines frühen Todes nicht zustande gekommen, ${ }^{48}$ so konnte die Akademiegründung des katholischen Fürsten István Báthori in einem mehrheitlich protestantischen Land nur einen vorübergehenden Erfolg haben. Der polnische König und siebenbürgische Fürst Báthori gründete 1581 mit Hilfe der Jesuiten eine katholische Hohe Schule in Klausenburg. Die Societatis Jesu Academia Claudiopolitana war eine Zwei-Fakultäten-Universität mit einer Ausbildung in Philosophie und Theologie, die allen Konfessionen offen stand. Infolge der von den Jesuiten eingeführten neuen Lehrmethoden nahm die Zahl der protestantischen Studenten an der katholischen Akademie, die auch akademische Grade erteilte, stetig zu. Nicht zuletzt deshalb beschloss der siebenbürgische Landtag nach dem Tod des Fürsten 1588 nicht nur die Schließung der Bildungsanstalt, sondern 1603 auch den Abriss des Gebäudes mit der Begründung, dass die Akademie das konfessionelle Gleichgewicht im Fürstentum gefährde. ${ }^{49}$

\section{Unmittelbare Kontakte zu Sturm und zur Straßburger Akademie}

Während die meisten Schulmänner in Ungarn und Siebenbürgen Sturms Methode nur aus seinen Schriften kennen lernen konnten, kamen einige peregrini mit dessen Pädagogik in unmittelbaren Kontakt. Die Straßburger Schule, die zwischen 
1538 und 1621 stufenweise zu einer Semi-Universität, dann zu einer Volluniversität ausgebaut wurde, besuchten vor 1621 nach heutigem Wissensstand ${ }^{50}$ nur wenige, etwa 30, Studenten aus Ungarn und Siebenbürgen. ${ }^{51}$ Doch unter ihnen befanden sich einige Hochadlige, die Straßburg in Begleitung ihrer Privatlehrer gerade wegen der von Sturm ausgearbeiteten Methode des Rhetorikunterrichts, die nach 1581 auch von dessen Nachfolger Melchior Junius fortgesetzt wurde, aufsuchten. Nach ihrer Peregrination bekleideten diese Studenten wichtige Positionen in der Landesverwaltung, wie etwa die evangelisch-lutherischen Adligen Baron Péter Révay als Obergespan des Komitats Turz, dann als königlicher Rat und Kronhüter, Zsigmond Balassa als Obergespan des Komitats Neograd oder Graf Szaniszló Thurzó als Palatin von Ungarn, das heißt Stellvertreter des Königs.

In Straßburg studierten auch für die ungarische Kulturgeschichte bedeutende Persönlichkeiten wie zwischen 1590 und 1592 der reformierte Geschichtsschreiber, Jurist, Dichter, Übersetzer und nicht zuletzt Schulmann János Baranyai Decsi oder zwischen 1593 und 1596 der ebenfalls reformierte Theologe, Wandergelehrte, Übersetzer und unter anderem Lektor der Lateinschule in Oppenheim am Rhein Albert Szenci Molnár. Damit zeigt die ungarisch-siebenbürgische Peregrination beim heutigen Stand der Forschung mehr Ähnlichkeiten zu der zahlenmäßig kleinen böhmischen als zu der wesentlich intensiveren polnisch-litauischen Peregrination in Straßburg. ${ }^{52}$

Die peregrini spielten auch für die Bekanntmachung der methodus Sturmiana im Rhetorikunterricht eine wichtige Rolle. Da der Rhetorik sowohl als Erkenntnismethode als auch als Grundlagenwissenschaft die Aufgabe zukam, die scholastische Logik zu ersetzen, rückte überall in den protestantischen Schulen die Praxis des Rhetorikunterrichts in den Mittelpunkt. Melanchthons diesbezügliche Lehrbücher, die zwar für das Lernen der Theorie, nicht aber für die Praxis geeignet waren, wurden rasch durch die von Sturm und von Junius abgelöst. Anstelle der praecepta der grammatischen, poetischen und rhetorischen Vorschriften rückten nun das Lesen und Erklären (exercitatio und analysis) und die aktive Imitation (imitatio und genesis) der lateinischen Texte in den Vordergrund. Man verwendete die von Sturm erarbeitete Imitationsmethode und Lehrtexte, vor allem seine Schulausgabe der Briefe Ciceros.

Auch in den ungarischen und siebenbürgischen Schulen lehrte man Rhetorik nach der Straßburger Methode und anhand der Sturm'schen Schulausgabe der Werke von Cicero. ${ }^{53}$ Der Rektor der Neusohler Schule, Abraham Schremmel aus Straßburg, schrieb die Benutzung der Schulausgabe der Briefe Ciceros von Sturm vor. Auch nach den Schulordnungen von Schemnitz 1587, von Leutschau 1589 oder von Modern 1594 lernten die Schüler aus Sturms Lehrbuch. ${ }^{54}$ Dass dieses Lehrbuch in Ungarn allgemein verbreitet war, beweist das Nachlassinventar des Kaschauer Buchhändlers Johann Gallen aus dem Jahr 1583. Nach der Bücherliste hatte er nicht weniger als 23 Exemplare von Sturms Briefausgabe auf Lager, wo- 
bei andere Bücher, etwa Schriften von Luther, nur in wenigen Exemplaren vorrätig waren. ${ }^{55}$

Einer der ungarischen peregrini in Straßburg, der nachweislich selbst im Unterricht tätig wurde, war der kroatischstämmige Baron Gergely Horváth (Gradeczi) Stansith (1558-1597). Er studierte zwischen 1574 und 1581 in Padua und 1581 in Straßburg. Dort lernte er nicht nur bei Sturm, sondern wohnte auch bei dem „deutschen Cicero“. Auch zu Sturms Gegner und Befürworter der Formula Concordiae, Professor Johannes Pappus, pflegte der orthodoxe Lutheraner aus Ungarn gute Kontakte. Seine Kavalierstour führte Horváth aus dem Elsass nach Basel, wo er mit dem lutherischen Theologen und Antistes der Basler Kirche sowie mehrfachen Rektor der Universität, Simon Sulzer, selbst ein Absolvent der Straßburger Akademie, in engere Verbindung kam. In Genf, wo er ein halbes Jahr verbrachte, machte er Bekanntschaft mit Béze, anschließend in Dresden mit Jakob Andreae, durch dessen Vermittlung 1577 die Konkordienformel zustande gekommen war.

In seine Heimat zurückgekehrt gründete Horváth auf seiner Familienburg im oberungarischen Nehre ein Gymnasium. Die Lehrer berief er aus dem Ausland, wobei der erste, Albert Grawer, zusammen mit ihm in Ungarn eintraf. Der spätere Professor für Theologie und mehrmalige Rektor der Universität Jena, Grawer, wurde Horváth von Ägidius Hunnius dem Älteren, gleichfalls einem lutherischen Theologen, empfohlen. Über die Schule ist sonst wenig bekannt, doch es ist überliefert, dass Grawer dort Philosophie und Theologie unterrichtete, wobei zu seinen besonderen Aufgaben auch die Interpretation der zwischen den Konfessionen debattierten theologischen Fragen gehörte. Der erste Schulrektor wurde der in Tangermünde gebürtigte Christoph Gera, der 1594 von der Straßburger Akademie nach Ungarn kam. Ihm folgte Nikolaus Erhard aus dem pfälzischen Dahlheim, der sein Studium in Heidelberg absolvierte. Horváth selbst unterrichtete an seiner Schule Dialektik, Ethik und Rhetorik, doch bevor das Gymnasium hätte ausgebaut werden können, starb er 1597, wodurch der Niedergang der Schule begründet wurde. ${ }^{56}$

$\mathrm{Zu}$ den Vermittlern der methodus Sturmiana kann sicherlich auch János Baranyai Decsi (ca. 1560-1601) gezählt werden, der das Studium in Straßburg mit dem Magistergrad beendete. 1591 legte er eine Arbeit in Philosophie unter dem Titel „Synopsis Philosophiae“ bei Johann Ludwig Hauvenreuter, einem Straßburger Vertreter der aristotelischen Philosophie, vor. Baranyai Decsi behandelte darin das System der theoretischen und praktischen Philosophie und fasste in 570 Thesen Wissensbereiche der Disziplin von der Mathematik über die Physik, Metaphysik, Ethik, Politik bis zur Wirtschaft zusammen. ${ }^{57}$ Die Grundlagen einiger dieser Fächer hatte er vielleicht auch seinen Schülern an der reformierten Schule in dem siebenbürgischen Neumarkt an der Marosch vermittelt, an der er zwischen 1593 und 1601 als Rektor tätig war. Die Schule hat sich unter seiner Leitung zu 
einer Bildungsanstalt mit drei Lehrern entwickelt. Sicherlich benutzte Baranyai Decsi im Unterricht auch sein 1598 verlegtes Buch über die ungarischen Sprichwörter und Redewendungen „Adagiorum graeco-latino-ungaricorum chiliades quinque“, dessen Nutzen er als „Reste und Funken der alten Philosophie und Gelehrsamkeit" für die Wissenschaften, insbesondere für die Philosophie und Rhetorik, hervorhob. Einen Anstoß zu diesem Buch gaben ihm vielleicht die von seinem Straßburger Lehrer Hauvenreuter 1573 publizierten „Adagia classica scholis Argentinensibus digesta“". ${ }^{58}$

Auf die Bedeutung eines kürzeren oder längeren Besuchs der Straßburger Akademie weist der Lebensweg von Albert Szenci Molnár (1574-1639) hin. Nach einem Schulbesuch in Gönc und Debrecen ging er 1590 über Wien, Prag, Dresden, Wittenberg und Heidelberg nach Straßburg, wo er sich am 7. Mai 1593 immatrikulieren ließ, nachdem er von Philipp Glaser examiniert und in die zweite Klasse unter dem Klassenlehrer Joseph Lang aufgenommen worden war. Laut der Eintragung in seinem Tagebuch erhielt Szenci Molnár auch einen Platz im Collegium Wilhelmitanum für ärmere Schüler, dessen Leiter damals Johannes Pappus war. Nach einem Examen am 1. April 1594 wurde er in die von Johannes Bentz geleitete erste Klasse aufgenommen. Im April des folgenden Jahres schloss er das Gymnasium erfolgreich ab und erhielt vom Rektor Pappus die Genehmigung, die lectiones publicae zu besuchen. Im Juli 1596 wurde aber Szenci Molnár wegen seines konfessionellen Bekenntnisses von der Akademie verwiesen, da er zusammen mit den Straßburger Reformierten regelmäßig nach Bischwiller zum Abendmahl ging. ${ }^{59}$

Trotz des Verweises nahm der Studienaufenthalt in Straßburg für seine spätere Laufbahn eine entscheidende Bedeutung ein. Ein Gespräch mit Johannes Pappus, der bei dem ungarischen Studenten nachfragte, ob die Bibel schon ins Ungarische übersetzt und ob ein lateinisch-ungarisches und ungarisch-lateinisches Wörterbuch vorhanden wäre, gab ihm den Anstoß, das Wörterbuch später anzufertigen und sich verstärkt Übersetzungsarbeiten zu widmen. Er schrieb und publizierte 1604 ein ungarisch-lateinisches und lateinisch-ungarisches Wörterbuch und übertrug unter anderem 1607 die Psalmen Davids, Calvins „Institutio“ sowie den Heidelberger Katechismus ins Ungarische. Nicht zuletzt gab er 1608 auch eine revidierte Übersetzung der Károlyi-Bibel heraus.

\section{Mittelbare Einflüsse: Sturms „Scholae Lauinganae“ in Ungarn und Herborns Vermittlung in Siebenbürgen am Anfang des 17. Jahrhunderts}

Das Straßburger Vorbild beeinflusste die Gestaltung des höheren Schulwesens in zahlreichen deutschen und außerdeutschen Territorien in unterschiedlicher, mittelbarer oder unmittelbarer Form. Einen unmittelbaren Kontakt zu Straßburg 
konnte das Gymnasium Palatinum Herzog Wolfgangs von Zweibrücken und Neuburg zu Lauingen an der Donau aufweisen, dessen Lehrplan Sturm selbst verfasst hatte. Der lutherische Pfalzgraf lud 1564 den Rektor Johannes Sturm aus Straßburg ein, um die innere Organisation des neuen Landesgymnasiums für das Herzogtum Pfalz-Neuburg zu vollenden, das 1562/1563 seine Tätigkeit begann. Sturm sah für das Gymnasium in Lauingen anstelle der zehn nur vier Klassen im Anschluss an die städtische Vorbereitungsschule vor, sowie lectiones publicae über Theologie, Physik, Mathematik, Ethik, Politik, Dialektik und Rhetorik sowie Jurisprudenz. Nach dem Muster seiner Studienanleitung von 1538 für das Straßburger Gymnasium verfasste Sturm eine solche auch für das Gymnasium von Lauingen, die „Scholae Lauinganae“, und gab diese zusammen mit der ebenfalls von ihm verfassten Schulordnung 1565 im Druck heraus. ${ }^{60}$

Diese auf vier Klassen und öffentliche Vorlesungen komprimierte Form der Straßburger Akademie konnte nicht nur in den kleineren deutschen Territorien oder Städten, sondern auch für jene protestantischen Zentren im Donau- und Karpatenraum als Muster dienen, die sich konfessionspolitisch in einer unsicheren Lage befanden und über beschränkte finanzielle Möglichkeiten zur Aufrechterhaltung einer universitätsähnlichen Bildungsanstalt verfügten. ${ }^{61}$ Eines dieser politischen und kulturellen Zentren im Königreich Ungarn war Pressburg, die provisorisch eingerichtete Hauptstadt. Nach Ofens Eroberung durch die Osmanen im Jahr 1541 wurde die königliche Freistadt Pressburg in der unmittelbaren Nähe der kaiserlichen Residenzstadt Wien zum neuen Sitz der königlichen und ständischen Verwaltung.

Die geographische Lage und die hervorgehobene Funktion Pressburgs verhinderten aber jede Bestrebung der Bewohner im 16. Jahrhundert, die Reformation einzuführen. Dies änderte sich nach dem von István Bocskai und seinen Truppen erkämpften Religionsfrieden vom 23. Juni 1606, als auch den königlichen Freistädten die freie Religionsausübung eingeräumt wurde. In Pressburg kam es unmittelbar danach zur Gründung einer lutherischen Kirchengemeinde, der sich die Mehrheit der Bewohner unter der Leitung der angesehenen Patrizierfamilien anschloss. Bereits am 2. August 1606 wandte sich der Stadtmagistrat an den Neuburger Pfalzgrafen Philipp Ludwig sowie seinen Hofpfarrer und zugleich Rektor des Gymnasiums zu Lauingen, Jacob Heilbrunner, mit der Bitte, einen im evangelischen Glauben festen Pfarrer für die Gemeinde und einen gelehrten Mann für das geplante Gymnasium mit der Begründung zu suchen und nach Pressburg zu entlassen. ${ }^{62}$ Warum vom Pressburger Stadtmagistrat gerade Pfalz-Neuburg ausgewählt wurde, geht aus den bisher bekannten Quellen nicht hervor. Möglicherweise gab es regelmäßige Beziehungen von Kauf- und Schiffleuten der beiden an der Donau liegenden Städte Neuburg und Pressburg und vielleicht auch Kontakte zwischen den Evangelischen in Pressburg und Heilbrunner. ${ }^{63}$ Fest steht jedoch, 
dass schon wenige Wochen später eine positive Antwort aus Neuburg in Ungarn eintraf.

Magister David Kilger, Professor am Gymnasium in Lauingen, ${ }^{64}$ erklärte sich bereit, die von den Pressburgern gewünschte Partikularschule nach dem Muster der Lauinger Schule einzurichten, wozu er auch die Genehmigung des Pfalzgrafen erhielt. ${ }^{65}$ In einer getrennten Instruktion an Kilger bekräftigte der Pressburger Stadtmagistrat seinen Wunsch, eine Partikularschule einzurichten, wo ,neben den gewöhnlichen freyen Künsten [...] Grammatica, Dialectica, Rhetorica, Arithmetica et Musica, und denen gebührlichen Sprachen, Griechisch und Latein in soluta et ligata oratione" unterrichtet werden sollten. Den Unterricht wünschte der Magistrat so zu gestalten ,wie die Classes der hochlöblichen Schule zu Lauingen jetziger Zeit besetzet seynd, dabey der Herr rector die primam classem versehen soll und die lectiones, entweder wie sie bey gemeldter fürstlichen Schule geordnet, oder wie es künftig Ihme nach dieser Orten Gewohnheit am besten zu seyn bedünken wird, verrichten, doch dass er, neben den andern lectionibus, auch eine theologicam lectionem verrichte. Für allen Dingen aber alle Zeit zur halben Jahreszeit ein examen halte, und sonst andere exercitationes anordne $[\ldots]^{\text {“ }} .{ }^{66}$

Kilger traf - zusammen mit Magister Adam Tettelbach, ${ }^{67}$ der neben Pfarrer Andreas Reuß zunächst als Diakonus der Gemeinde dienen sollte ${ }^{68}-$ am 2. Dezember 1606 ein, und die Schule wurde schon kurz darauf, im Januar 1607, eröffnet. Dank des Pfalz-Neuburger Professors konnte in den folgenden Jahren das vom Magistrat gehegte Ziel verwirklicht werden. Das Pressburger Gymnasium wurde mit weiteren Klassen ausgebaut, ${ }^{69}$ was Kilgers Nachfolgern zu verdanken war, die - nachdem das Herzogtum Pfalz-Neuburg 1616 vom katholisch gewordenen Pfalzgrafen Wolfgang Wilhelm rekatholisiert wurde - abwechselnd aus Wittenberg und Straßburg eingeladen wurden. Aus Straßburg kamen 1627 Ernst Hilarius Binner und 1633 Jacob Johann Helgenmaier. ${ }^{70}$ Das Gymnasium von Pressburg gehörte mit Sicherheit zu den ersten Bildungsanstalten im Donau- und Karpatenraum, die nicht nur Sturms pädagogische Methode, sondern auch seine Schulstruktur bewusst eingeführt haben. ${ }^{71}$

In Siebenbürgen kam es in den 1620er Jahren zu einer zweiten Akademiegründung nach dem gescheiterten Versuch des István Báthori, bei welcher jetzt die Hohe Schule Herborn als eine dem Straßburger und Genfer Vorbild nachempfundene Bildungsanstalt ${ }^{72}$ eine besondere Rolle einnahm. Auf Initiative des reformierten Fürsten Gábor Bethlen genehmigte 1622 der siebenbürgische Landtag den Plan einer reformierten Akademie, wozu der Fürst drei Lehrer der Hohen Schule Herborn gewinnen konnte: den bekanntesten Professor der Akademie, Johann Heinrich Alsted sowie Philipp Ludwig Piscator und Johann Heinrich Bisterfeld. Dass sich Bethlen für die Herborner entschied, war nicht zuletzt Szenci Molnár zu verdanken, den der Fürst schon im Vorfeld seiner Bestrebungen um 
Informationen über die deutschen Schulsysteme gebeten hatte. Szenci Molnár präferierte die pfälzische Variante des Schul- und Unterrichtsmodells und ließ 1621 in der zweiten und ergänzten Auflage seines lateinisch-ungarischen Wörterbuchs unter dem Titel „Lexicon Latino-Graeco-Hungaricum“ Teile der in der Unteren Pfalz gültigen Schulordnung „Sylecta scholastica“ abdrucken und nach Ungarn und Siebenbürgen schicken. Diese hatte auch einen gewissen Einfluss auf die 1621 neu zusammengestellte Schulordnung des reformierten Kollegiums von Sárospatak ausgeübt. ${ }^{73}$ Szenci Molnár schwebte die 1584 gegründete nassau-dillenburgische Akademie in Herborn sicherlich wegen ihrer umfassenden und praxisorientierten Ausbildung und der erfolgten Einführung der zu jener Zeit als modern geltenden didaktischen Prinzipien des so genannten Ramismus als Vorbild vor, wodurch ja die Herborner Anstalt international hohe Beachtung genoss. ${ }^{74}$ Nach seinen Studien in Straßburg und Heidelberg studierte Szenci Molnár 1601/1602 selbst in Herborn und pflegte zu den Professoren Johann Piscator, Matthias Martinius und Georg Pasor enge Beziehungen. ${ }^{75}$

Ähnlich wie Báthori plante auch Bethlen eine schon bestehende Schule zur Akademie auszubauen, wozu er schließlich die Schule in seiner Residenz WeiBenburg bestimmte. Die Herborner Professoren Alsted, Piscator und Bisterfeld hatten bereits am 10. Februar 1630 ihre Vorschläge zur Struktur der Akademie eingereicht, um der siebenbürgischen Schule - wie sie schrieben - nach deutschem und französischem Muster unverzüglich zur Blüte zu verhelfen. ${ }^{76}$ Der Unterricht sollte im Gymnasium in fünf Jahrgangsklassen unter der Leitung von Klassenlehrern erteilt werden, während an der Akademie vier Professoren - zwei für die Theologie (das Alte und Neue Testament und die loci communes), ein dritter für die Philosophie (Logik, Metaphysik, Physik, Mathematik und praktische Philosophie) und ein vierter für die Sprachen (Hebräisch, Griechisch und Latein) - angestellt werden sollten. Die Gesetze der Akademie stellten die Herborner Professoren anhand der Gesetze der Heidelberger Universität, des Heidelberger Pädagogiums und des Weißenburger Gymnasiums zusammen. ${ }^{77}$ Die Weißenburger Akademie, die schließlich nur mit der theologischen Fakultät ihre Tätigkeit aufnehmen konnte, weil Bethlens Nachfolger, György I. Rákóczi, anstelle der akademischen Ausbildung die Elementarschulen und Gymnasien förderte, wurde 1658 von den tatarischen Hilfstruppen der Osmanen zerstört, in deren Folge die Akademie auf das Niveau der reformierten Kollegien zurückfiel.

\section{Das höhere Schulwesen in Ungarn und Siebenbürgen im 16. Jahrhundert und in den ersten Jahrzehnten des 17. Jahrhunderts}

Anhand der bisherigen Forschungen zeichnet sich in Ungarn und Siebenbürgen im 16. Jahrhundert eine Entwicklung ab, die stark an den mittel- und westeuropäi- 
schen Modellen partizipierte und somit keine eigenständigen Schultypen hervorbrachte. Allerdings haben die Protestanten in Ungarn und Siebenbürgen entsprechend der spezifischen politischen und konfessionellen Lage im Donau- und Karpatenraum ihre eigenen Varianten der verbreiteten Schultypen entwickelt.

Die am Anfang des 16. Jahrhunderts im Sinne des Humanismus modernisierten Lateinschulen haben sich auch in Ungarn und Siebenbürgen infolge der Reformation inhaltlich und damit auch strukturell weiterentwickelt. In der zweiten Hälfte des 16. Jahrhunderts boten die frequentierten Schulen bereits ein Lehrprogramm an, das über das Trivium weit hinausging. Vergleicht man allerdings das Angebot dieser lutherischen und reformierten Schulen, so kann festgestellt werden, dass Lutheraner und Reformierte einen unterschiedlichen Weg zur höheren Ausbildung eingeschlagen haben. Die zentralen Schulen der Lutheraner erweiterten ihr Lehrangebot mit Fächern des Quadriviums, eine akademische Ausbildung in Theologie wurde aber zunächst nicht angeboten. Der Grund dafür war sicherlich die herausragende Stellung der Universität Wittenberg bei der Pfarrerausbildung für den Donau- und Karpatenraum. ${ }^{78}$ In Wittenberg wurde ein Großteil der neuen lutherischen Elite sowohl für Ungarn als auch für Siebenbürgen ausgebildet und dort wurden anfangs auch ihre Geistlichen ordiniert.

Dagegen fand in den frequentierten Schulen der Reformierten mit der Einführung einer akademischen Ausbildung in Theologie und Philosophie eine Erweiterung des Lehrangebots statt. Einer der Gründe dafür war sicherlich die Tatsache, dass die Reformierten, die einerseits mit den Lutheranern und Antitrinitariern, andererseits mit den Katholiken heftige theologische Auseinandersetzungen führen mussten, auf besonders glaubensfeste und theologisch gut ausgebildete Prediger und Lehrer angewiesen waren.

Ein weiteres Spezifikum der Schulentwicklung im Donau- und Karpatenraum war, dass während des ganzen 16. Jahrhunderts sowohl in den lutherischen Gymnasien als auch in den reformierten Kollegien Melanchthons Bildungsideal bestimmend war. Sturm konnte im 16. Jahrhundert mit dem praeceptor Germaniae nicht wetteifern, nicht zuletzt deshalb, weil sein aufwendiges Straßburger Gymnasium illustre unter den wesentlich bescheideneren Verhältnissen im Königreich Ungarn und im Fürstentum Siebenbürgen nicht als Vorbild dienen konnte. Allerdings war der Unterschied zwischen der protestantischen Gelehrtenschule Melanchthon'scher und Sturm'scher Prägung nicht gravierend, denn wer sie durchlief, wurde grundlegend im Geist des humanistischen Klassizismus erzogen. ${ }^{79}$ So konnten gerade außerhalb der deutschsprachigen Gebiete beide Modelle harmonisierend miteinander verbunden werden. 


\section{Anmerkungen}

1 Márta Fata: Deutsche und schweizerische Einflüsse auf die Reformation in Ungarn im 16. Jahrhundert. Aspekte der frühneuzeitlich-vormodernen Identität zwischen Ethnie und Konfession. In: Wilhelm Kühlmann - Anton Schindling (Hg.): Deutschland und Ungarn in ihren Bildungs- und Wissenschaftsbeziehungen während der Renaissance (= Contubernium 62). Stuttgart 2004, S. 53-91.

2 Richárd Hörcsik: Kálvin 16. századi magyarországi recepciója [Calvins Rezeption im 16. Jahrhundert]. In: Sándor Fazekas (Hg.): Kálvin idöszerüsége. Tanulmányok Kálvin János teológiájának maradandó értékéröl és magyarországi hatásáról. Budapest 2009, S. 13-37.

3 András Szabó: Ungarische Studenten in Wittenberg 1555-1592. In: Ders. (Hg.): Iter Germanicum. Deutschland und die Reformierte Kirche in Ungarn im 16.-17. Jahrhundert. Budapest 1999, S. 154-168, hier S. 157.

4 Von diesen Studenten kamen nachweislich sieben aus Siebenbürgen, darunter György Enyedi, der spätere Bischof der Antitrinitarier oder der Calvinist Gergely Belényesi, Calvins erster Student aus Ungarn. Vgl. Miklós Szabó - Sándor Tonk: Erdélyiek egyetemjárása a korai újkorban 1521-1700 [Die Peregrination der Siebenbürger in der frühen Neuzeit 1521-1700]. Szeged 1992.

5 Gusztáv Bölcskei: A kezdetektől a váradi iskola beolvadásáig (1660) [Von den Anfängen bis zur Integration der Schule von Wardein (1660)]. In: József Barcza (Hg.): A Debreceni Református Kollégium története. Budapest 1988, S. 9-42, hier S. $25 \mathrm{f}$.

6 Ulrich Im Hof: Die reformierten Hohen Schulen und ihre schweizerischen Stadtstaaten. In: Erich Maschke - Jürgen Sydow (Hg.): Stadt und Universität im Mittelalter und in der früheren Neuzeit. Sigmaringen 1977, S. 53-70; Ders.: Die Entstehung der reformierten Hohen Schule. Zürich (1525) - Bern (1528) - Lausanne (1537) - Genf (1539). In: Peter Baumgart-Notker Hammerstein (Hg.): Beiträge zu Problemen deutscher Universitätsgründungen der frühen Neuzeit (= Wolfenbütteler Forschungen 4). Nendeln 1978, S. 243-262; Anton Schindling: Jean Calvin et l'École de Jean Sturm. In: Matthieu Arnold (Hg.): Jean Calvin: Les années strasbourgeoises (1538-1541). Actes de colloque de Straßbourg (8-9 octobre 2009) à l'occasion du 500 e anniversaire de la naissance du Réformateur. Strasbourg 2010, S. 79-92.

7 Aus der überaus reichen Literatur vgl. u. a. Gerhard Arnhardt - Gerd-Bodo Reinert: Philipp Melanchthon. Architekt des neuzeitlich-christlichen deutschen Schulsystems. Studienbuch. Donauwörth 1997; Heinz Scheible: Die Reform von Schule und Universität in der Reformationszeit. In: Luther Jahrbuch 66 (1999), S. 237-262; Hermann-Adolf Stempel: Melanchthons pädagogisches Wirken. Bielefeld 1979; Philipp Melanchthon und das städtische Schulwesen. Begleitband zur Ausstellung. Hg. v. der Lutherstadt Eisleben. Halle 1997.

8 Arno Seifert: Das höhere Schulwesen. Universitäten und Gymnasien. In: Christa Berg (Hg.): Handbuch der deutschen Bildungsgeschichte. 6 Bde. München 1989-2005, hier Bd. 1, 1996, S. 197-345, S. 279.

9 Unterricht der Visitatoren an die Pfarrherrn im Kurfürstentum zu Sachsen, Wittenberg 1528. In: Hans-Ulrich Delius (Hg.): Martin Luther. Studienausgabe. 6 Bde. Berlin 1979-1999, hier Bd. 3, 1983, S. 406-462.

10 Ebenda.

11 Anton Schindling: Die Straßburger Hochschule zur Zeit des Späthumanismus um 1600. In: Peter Herde - Anton Schindling (Hg.): Universität Würzburg und Wissenschaft in der Neuzeit. Beiträge zur Bildungsgeschichte gewidmet Peter Baumgart anlässlich seines 65. Geburtstages (= Quellen und Forschungen zur Geschichte des Bistums und Hochstifts Würzburg 53). Würzburg 1998, S. 95-107, hier S. 100f. 
12 Notker Hammerstein: Res publica litteraria. Ausgewählte Aufsätze zur frühneuzeitlichen Bildungs-, Wissenschafts- und Universitätsgeschichte. Berlin 2000; Ders.: Bildung und Wissenschaft vom 15. bis zum 17. Jahrhundert. München 2003; Anton Schindling: Bildungsinstitutionen im Heiligen Römischen Reich deutscher Nation als Ziele der studentischen Migration. Wanderungen im Zeichen von Konfession und geistigen Strömungen. In: Márta Fata - Gyula Kurucz - Anton Schindling (Hg.): Peregrinatio Hungarica. Studenten aus Ungarn an deutschen und österreichischen Hochschulen vom 16. bis zum 20. Jahrhundert (= Contubernium 64). Stuttgart 2006, S. 39-54.

13 Anton Schindling: Humanistische Hochschule und freie Reichsstadt. Gymnasium und Akademie in Straßburg 1538 bis 1621 (= Veröffentlichungen des Instituts für Europäische Geschichte Mainz 77). Wiesbaden 1977; Bernd Schröder: Leben und Werk Johannes Sturms. In: Ders. (Hg.): Johannes Sturm (1507-1589), Pädagoge der Reformation. Zwei seiner Schulschriften aus Anlass seines 500. Geburtstages. Lateinisch-deutsche Lese-Ausgabe. Jena 2009, S. 9-63.

14 Gustav Adolf Benrath (Hg.): Quellenbuch zur Geschichte der evangelischen Kirche in Schlesien. München 1992, S. $78 f$.

15 Gustav Bauch: Valentin Trotzendorf und die Goldberger Schule. Berlin 1921; Arno Lubos: Valentin Trotzendorf. Ein Bild aus der schlesischen Kulturgeschichte. Ulm 1962; Christine Absmeier: Das schlesische Schulwesen im Jahrhundert der Reformation. Ständische Bildungsreformen im Geiste Philipp Melanchthons (= Contubernium 74). Stuttgart 2011, S. 100-128.

16 Erika Kopp: A kálvinizmus hatása a magyar oktatásügyre [Die Auswirkung des Calvinismus auf das ungarische Unterrichtswesen]. In: Magyar Tudomány 171/2 (2010), S. 159-168.

17 Die Forschung verfügt nur stellenweise über Statistiken. Im Fall der siebenbürgischen Reformierten im 16. Jahrhundert sind allerdings in den 360 reformierten Kirchengemeinden 240 Schulen, meist kleine Dorfschulen, belegt. Vgl. dazu Attila K. Szabó: Magyar neveléstörténeti kronológia különös tekintettel Erdélyre [Chronologie der ungarischen Bildungsgeschichte mit besonderem Blick auf Siebenbürgen]. In: Magiszter 2 (2004), S. 116.

18 Der erste Beschluss über die Errichtung von Volksschulen wurde in Ungarn von der katholischen Synode zu Tyrnau 1560 unter dem Graner Erzbischof Miklós Oláh angenommen. Vgl. István Mészáros: A magyar nevelés- és iskolatörténet kronológiája 996-1996 [Die Chronologie der ungarischen Bildungs- und Schulgeschichte 996-1996]. Budapest 1996, S. $18 \mathrm{f}$.

19 Vgl. u. a. Vilmos Fraknói: A hazai és külföldi iskolázás a XVI. században [Schulunterricht im In- und Ausland]. Budapest 1873; Ernő Fináczy: A magyarországi középiskolák múltja és jelene [Die Vergangenheit und Gegenwart der Mittelschulen in Ungarn]. Budapest 1896; Remig Békefi: A népoktatás története Magyarországon 1540-ig [Die Geschichte des Volksunterrichts in Ungarn bis 1540]. Budapest 1906; Lajos Gál: Protestáns iskolák és tanitók Magyarországon a XVI. században [Protestantische Schulen und Lehrer in Ungarn im 16. Jahrhundert]. Tiszaföldvár 1940, S. 28-40.

20 István Mészáros: XVI. századi városi iskoláink és a „studia humanitatis “ [Unsere Stadtschulen im 16. Jahrhundert und die „studia humanitatis“]. Budapest 1981.

21 Ders.: Az iskolaügy története Magyarországon 996-1777 között [Die Geschichte des Schulwesens in Ungarn von 996 bis 1777]. Budapest 1981, S. 217-242.

22 Újfalvi studierte als Absolvent des Sárospataker Reformierten Kollegiums ab 1591 zuerst in Wittenberg, dann ab 1595 in Heidelberg. Sein pädagogisches Vorbild war der Sárospataker Professor und Melanchthon-Schüler Balázs Szikszai Fabricius, weshalb die ungarische Forschung vor allem Melanchthons Wirkung in seinen humanistischen Leitgedanken wie auch in seiner Vorstellung eines konfessionellen Friedens zwischen Lutheranern und 
Reformierten hervorhebt. Vgl. dazu Balázs Nagy Kálózi: Pedagógusképzés a debreceni föiskolában a XVI. században. II. rész. Szilvásújfalvi Imre pedagógiája [Die Ausbildung der Pädagogen an der Debrecener Hochschule im 16. Jahrhundert. Teil 2. Die Pädagogik von Imre Szilvásújfalvi]. In: Református Egyház 1968, S. 13-20; Pál Ács: Újfalvi Imre: „, Tiszta énekek“ - Újfalvi Imre: Keresztényi énekek (1602) [Imre Újfalvi: „Reine Lieder“ - Imre Újfalvi: Christliche Lieder (1602)]. In: Ders.: „Elváltozott idők“. Irányváltások a régi magyar irodalomban (= Régi Magyar Könyvtár. Tanulmányok 6). Budapest 2006, S. 47-108, bes. S. 50-55. In der Tat betonte Újfalvi in seiner Studienanleitung von 1597 die unzertrennbare Einheit von Bildung und religiösem Leben als Ziel der Schulbildung. Doch gerade mit der Abfassung eines ausführlichen pädagogischen Wegweisers für den Unterricht der Elementarstufe, welcher den ersten bekannten dieser Art in Ungarn darstellt, folgte er vielleicht dem Beispiel von Johannes Sturm, der seine Lehrinhalte und pädagogischen Methoden in detaillierten Studienanleitungen festhielt. Ebenfalls 1597 ließ Újfalvi das Lehrbuch „Nomenclatura seu Dictionarium Latino-Ungaricum“ seines Vorbildes Szikszai Fabricius in erweiterter Form nachdrucken, in deren Einleitung er einen Brief von Sturm an den Straßburger Schuldiener Magister Heinrich Schirner über die Notwendigkeit und den Nutzen der lateinischen Sprache, sicherlich nicht zufällig, mit abdruckte. Vgl. dazu Bölcskei: A kezdetektöl a váradi iskola beolvadásáig, S. 24. Imre Újfalvi: Admonitiones de ratione discendi atque docendi in ultima seu tertia classe, Debrecen 1597. Abgedruckt bei István Mészáros: XVI. századi városi iskoláink, S. 203-217, S. 204f. Újfalvi verfasste nur den ersten Teil für die Elementarstufe seiner sicherlich als dreiteilig geplanten Studienanleitung für die Debrecener Schule.

24 Ebenda.

25 Aladár Molnár: A közoktatás története Magyarországon a XVIII. században [Die Geschichte der Volksbildung in Ungarn im 18. Jahrhundert]. 2 Bde. Budapest 1881, hier Bd. 1, S. 54-63.

26 Aus der reichen Forschungsliteratur zu Stöckel vgl. u. a. Klára Szilasi: Stöckel Lénárd Zsuzsanna-drámája és a bártfai német iskolai szinjáték a XVI. században [Das SusanneDrama von Leonhard Stöckel und das Bartfelder deutsche Schultheater im 16. Jahrhundert]. Budapest 1918; Daniel Škoviera: Epistulae Leonardi Stöckel. In: Zbornik Filozofickej Fakulty Univerzity Komenského Graecolatina et Orientalia VII/VIII (1976), S. 265-359; Ders.: Leonard Stöckel und die Antike. In: Zbornik Filozofickej Fakulty Univerzity Komenského Graecolatina et Orientalia XI/XII (1979/80), S. 41-58; Max Josef Suda: Der MelanchthonSchüler Leonhard Stöckel und die Reformation in der Slowakei. In: Karl Schwarz (Hg.): Die Reformation und ihre Wirkungsgeschichte in der Slowakei. Wien 1996, S. 50-66; Karl Schwarz: Praeceptor Hungariae. Über den Melanchthonschüler Leonhard Stöckel (1510-1560). In: Acta Collegii Evangelici Prešoviensis V (2000), S. 47-67.

27 Daniel Škoviera: Bardejovčan Valentín Ecchius a jeho učebnica Ars versificandi. Bratislava 2002; Márta Fata: Humanistische Einflüsse oberdeutscher und melanchthonischer Provenienz im ungarischen Bartfeld. In: Ulrich A. Wien - Krista Zach (Hg.): Politik, Religion und Kunst im 16. Jahrhundert. Köln - Weimar - Wien 2004, S. 155-171, hier S. 158-161.

28 Leges Scholae Bartphensis. Diese erste Schulordnung aus dem Jahre 1540, deren Text nicht erhalten geblieben ist, wurde stets erneuert und erweitert. Eine erste bekannte, wahrscheinlich von der Eperiescher Synode von 1546 anerkannte Variante ist abgedruckt bei Johann Samuel Klein: Nachrichten von den Lebensumständen und Schriften Evangelischer Prediger in allen Gemeinden des Königreichs Ungarn. 2 Bde. Leipzig-Ofen 1789, hier Bd. 1, S. 332-341. Nachgedruckt bei Mészáros: XVI. századi városi iskoláink, S. 153-158.

29 „Hi conventus similes esse debent senatoriis, in quibus res utiles rei publicae quaerantur. Sint ergo colloquia de rebus grammaticis, aut dialecticis, aut rhetoricis, aut philosophicis, aut de 
natura rerum, aut moribus, aut theologicis."Zit. nach Mészáros: XVI. századi városi iskoláink, S. 154.

30 Gál: Protestáns iskolák, S. 30.

31 Die Schulordnung und Schulgesetze abgedruckt u. a. in Ludwig Binder: Johannes Honterus. Schriften, Briefe, Zeugnisse. Bukarest 1996, S. 161-163.

32 Ute Monika Schwob: Kulturelle Beziehungen zwischen Nürnberg und den Deutschen im Südosten im 14. bis 16. Jahrhundert (= Buchreihe der Südostdeutschen Historischen Kommission 22). München 1969, S. 132-135; Walter König: Johannes Honterus - Praeceptor Saxonum. In: Ders.: Schola seminarium rei publicae. Aufsätze zu Geschichte und Gegenwart des Schulwesens in Siebenbürgen und Rumänien (= Siebenbürgisches Archiv 38). KölnWeimar-Wien 2005, S. 21-39. Heydens Übungsbuch „Puerilia Colloquia“ wurde auch in den Schulen des Donau- und Karpatenraums verwendet. Vgl. dazu Bölcskei: A kezdetektöl a váradi iskola beolvadásáig, S. 23.

33 Ute Monika Schuller: Der Coetus am Honterus-Gymnasium zu Kronstadt in Siebenbürgen 1544-1941. Ein Beitrag zur Geschichte des Helfersystems, der Schülermitregierung und Schülermitverantwortung. München 1963.

34 Molnár: A közoktatás története, S. 114f.

35 Ernst Wagner (Hg.): Quellen zur Geschichte der Siebenbürger Sachsen 1191-1975 (= Schriften zur Landeskunde Siebenbürgens. Ergänzungsreihe 1). Köln-Wien 1976, S. 117.

36 Mészáros: XVI. századi városi iskoláink, S. 78-109.

37 Ebenda, S. 84

38 In der unteren und mittleren Stufe - meist aus Elementarklassen, Klassen für Grammatik, Poetik, Rhetorik bestehend - erfolgte der Unterricht im Rahmen der Trivialschule, in der höchsten Stufe wurden meist in zwei Klassen Philosophie und Theologie unterrichtet. Neben diesem so genannten vollständigen Kollegium gab es zwei einfachere Varianten. In der ersten Variante wurde in der obersten Stufe nur Theologie, aber keine Philosophie gelehrt, in der einfachsten Variante erfolgte nach der Elementarausbildung der Unterricht in der lateinischen Grammatik und gleich danach die Vermittlung von theologischen Kenntnissen. Vgl. dazu Mészáros: Az iskolaügy története, S. 238-254.

39 Dénes Dienes: A héber nyelv a Sárospataki Kollégiumban a 16-17. században [Die hebräische Sprache im Sárospataker Kollegium in dem 16. und 17. Jahrhundert]. In: Mária Kun-Judit Morvai (Hg.): Tanulmánykötet az 50 éves Marjovszky Tibor tiszteletére. Budapest 2003, S. 38-47.

40 Im Hof: Die Entstehung der reformierten Hohen Schule, S. 246f.

41 Dazu vgl. u. a. János L. Győri: Zur Bedeutung des Reformierten Kollegiums Debrecen für Kultur und Politik Ungarns vom 16. bis zum 19. Jahrhundert. In: Márta Fata - Anton Schindling (Hg.): Calvin und Reformiertentum in Ungarn und Siebenbürgen. Helvetisches Bekenntnis, Ethnie und Politik vom 16. Jahrhundert bis 1918 (= Reformationsgeschichtliche Studien und Texte 155). Münster 2010, S. 239-259.

42 Remig Békefi: Oláh Miklós nagyszombati iskolájának szervezete [Struktur der Tyrnauer Schule von Miklós Oláh]. In: Századok 31 (1897), S. 891-902; Aurelián Héts: A jezsuiták iskolái Magyarországon a 16. század közepén [Die Schulen der Jesuiten in Ungarn um die Mitte des 16. Jahrhunderts]. Pannonhalma 1938; Antal Petruch: A Jézustársaság mint tanítórend [Die Gesellschaft Jesus als Schulorden]. In: Béla Bangha (Hg.): A négyszázéves Jézustársaság. Budapest 1940, S. 175-201.

43 Mészáros: XVI. századi városi iskoláink, S. 167f.

44 Ebenda, S. 168f.

45 Huet ließ, um das Studium zu fördern, die Kapelle neben der Schule zur Bibliothek herrichten. Durch Ankauf zweier Häuser wurde die Schule auch äußerlich vergrößert und 1602 hielt Huet 
im Saal, den er selbst hatte schmücken und einrichten lassen, eine glanzvolle Rede zum Thema: „Die Schule, eine Pflanzstätte des Gemeinwesens“, wobei er den Wert der Schulbildung betonte und die Sorge für die Schule den Mitbürgern ans Herz legte. In seinem Testament schenkte er der Schule seine reiche Bibliothek und außerdem die Summe von 2000 Gulden. Vgl. August Schuster: Der Sachsengraf Albert Huet im Rahmen unserer Geschichte. Hermannstadt 1938.

46 Friedrich Teutsch: Kirche und Schule der Siebenbürger Sachsen in Vergangenheit und Gegenwart. Mit einem Überblick über die der ev. Landeskirche A. B. in Siebenbürgen angeschlossenen Kirchen. 2. Aufl. Hermannstadt 1923, S. 68f.; Hermann Jekeli: Die Entwicklung des siebenbürgisch-sächsischen höheren Schulwesens von den Anfängen bis zur Gegenwart. Mediasch 1930, S. 4-9.

47 Teutsch: Die siebenbürgisch-sächsischen Schulordnungen, S. XLVIII.

48 Er plante 1567 in Mühlbach eine Akademie u. a. mit der Einladung von Celsio Secundo Curio aus Basel, dann um 1570 von Peter Ramus aus Paris als leitendem Professor. Vgl. dazu László Szögi (Hg.): Régi magyar egyetemek emlékezete. Memoria universitatum et scholarum maiorum regni Hungariae 1367-1777. Válogatott dokumentumok a magyarországi felsöoktatás történetéhez [Ausgewählte Dokumente zur Hochschulbildung in Ungarn]. Budapest 1995, http://mek.niif.hu/01800/01882/01882.htm, letzter Zugriff, 14. Februar 2011.

Endre Veress: A kolozsvári Báthory-egyetem története lerombolásáig [Die Geschichte der Klausenburger Báthory-Universität bis zu deren Auflösung]. Kolozsvár 1906.

50 Da die ältesten Matrikeln der Straßburger Akademie verloren sind, versucht die ungarische und siebenbürgische Forschung aus verschiedenen Sekundärquellen den Kreis der peregrini in Straßburg zu erfassen.

51 Die Autorin konnte aus der ihr zur Verfügung stehenden Literatur folgende Personen zusammenstellen, wobei es zu betonen ist, dass diese Liste keineswegs vollständig ist: János Zsámboki (Johannes Sambucus) aus Tyrnau 1550-1552, János Drugnetius aus Kőrös 1552-1555, Gergely Horváth (Gradeczi) Stansith aus Westungarn 1580, Demeter Krakkai, Mihály Forgách, Zsigmond Máriássy und Zsigmond Pécsy 1586, Mihály Clementides aus Kirchdrauf 1588, Péter und Ferenc Révay aus Oberungarn 1589-1591, Pál und Zsigmond Balassa aus dem Komitat Nógrád 1591, Szaniszló Thurzó aus Oberungarn 1590, Samuel Spillenberger aus Leutschau 1593, Albert Szenci Molnár aus Szenc 1593-1595 und Johann Melczer aus Eperiesch 1595, Pál Szimai 1596. Auch Mihály Paksi Cormaeus war in Straßburg. Aus Siebenbürgen: János Baranyai Decsi 1589-1592 (eigentlich aus dem osmanisch besetzten Teil Ungarns) mit seinem Schüler Ferenc Bánffy, György Belényesi, Baron Alexander Somborius, Andreas Reichmund, Franz Listi, Gallus Rohrmann, Georg Deidrich, Georg Roth, Georg Ladislai, Johannes Budacker, Martin Hoggeus, Matthias Tatsnervs. Angaben zu den ersten Straßburg-Besuchern vgl. bei Frankl (Fraknói): A hazai és külföldi iskolázás, S. 284-286; Sándor Eckhardt: Magyar szónokképzés a XVI. századi Strasszburgban [Rhetorausbildung von Ungarn in Straßburg im 16. Jahrhundert]. In: Értekezések a Nyelv és Széptudományi Osztály Köréböl. 26 (1944), S. 345-378; Jean Bérenger: Strassburg és a reformáció megerősödése Magyarországon [Straßburg und die Verstärkung der Reformation in Ungarn]. In: A Ráday Gyüjtemény Évkönyve 4/5 (1984/85), S. 3-8, S. 6; András Szabó: Melanchthontól Lipsiusig. Tanárok, diákok és prédikátorok Sárospatakon 1562-1598 [Von Melanchthon bis Lipsius. Lehrer, Studenten und Prediger in Sárospatak 1562-1598]. In: Irodalomtudományi Közlemények XC (1986), S. 483-505, hier S. 496; Ders. (Hg.): Szenci Molnár Albert naplója [Das Tagebuch von Albert Szenci Molnár] (= Historia Litteraria 13). Budapest 2003, S. 112; Szabó - Tonk: Erdélyiek egyetemjárása, S. 5, 10, 55, 61, 69, 72, 89, 107, 163, 178. Einige dieser Studenten korrespondierten wie Sambucus oder Clementides mit Sturm oder mit anderen Personen in Straßburg. Vgl. zu dieser 
Korrespondenz Alfred Temesi: Humanisme franco-hongrois. In: Egyetemes Philologiai Közlöny 1938, S. 305-320. - Erst nach 1621 stieg die Zahl der peregrini mäßig an: Bis 1793 haben sich 205 Studenten aus Ungarn und Siebenbürgen dort immatrikuliert, von denen etwa 60 Prozent aus Ungarn und 40 Prozent aus Siebenbürgen kamen. Vgl. dazu Gustav C. Knod: Die alten Matrikeln der Universität Straßburg 1621 bis 1793. 3 Bde. Straßburg 1897-1902.

52 Martin Holý: Johannes Sturm, das Straßburger Gymnasium (Akademie) und die Böhmischen Länder in der zweiten Hälfte des 16. Jahrhunderts. In: Matthieu Arnold (Hg.): Johannes Sturm (1507-1589). Rhetor, Pädagoge und Diplomat. Tübingen 2009, S. 303-317. Zur polnischen Peregrination in Straßburg vgl. Zdzislaw Pietrzyk: Die Ausstrahlung Straßburgs im Zeitalter des Humanismus. Peregrinatio academica aus der polnisch-litauischen Republik und die Hohe Schule Johannes Sturms im 16. und 17. Jahrhundert. In: Zeitschrift für die Geschichte des Oberrheins 158 (2010), S. 193-240.

53 Gábor Kecskeméti: A genius iudiciale a 16-17. századi magyarországi irodalomban és irodalomelméletben [Genius iudiciale im 16. und 17. Jahrhundert in der ungarländischen Literatur und Literaturtheorie]. In: Irodalomtudományi Közlemények 105 (2001), S. 255-284, bes. S. 261.

54 Mészáros: XVI. századi városi iskoláink, S. 182, 185, 195; Ders.: Az iskolaügy története Magyarországon, S. 380.

55 Lajos Kemény: Egy XVI. századbeli könyvkereskedő raktára [Das Lager eines Buchhändlers aus dem 16. Jahrhundert]. In: Magyar Könyvszemle 20 (1895), S. 310-320, hier S. 312.

56 György Ráth : Gradeczi Horváth Gergely és Lám (Ambrosius) Sebestyén hitvitája [Religionsdisput zwischen Gergely Gradeczi Horváth und Sebestyén Lám (Ambrosius)]. In: Irodalomtudományi Közlemények 4 (1894), S. 150-167, 299-319, 412-427, hier S. 154-156.

57 Ágnes Kurcz: Baranyai Decsi János Sallustius-fordítása. Kísérő szöveg [SallustiusÜbersetzung des János Baranyai Decsi. Begleittext]. In: Béla Varjas (Hg.): Az Caius Crispus Sallustiusnak két históriája (= Bibliotheca Hungarica Antiqua 10). Beilage. Budapest 1979, S. 13 .

58 Zu Decsis Tätigkeit vgl. Samu Benkő u. a. (Hg.): Baranyai Decsi Csimor János emlékezete [Erinnerung an János Baranyai Decsi Csimor] (= Erdélyi Tudományos Füzetek 235). Kolozsvár 2011.

59 Zu den Angaben vgl. das Tagebuch von Szenci Molnár. Szabó (Hg.): Szenci Molnár Albert naplója, S. 56-58.

60 Ausführlich bei Anton Schindling: Humanistische Reform und fürstliche Schulpolitik in Hornbach und Lauingen. Die Landesgymnasien des Pfalzgrafen Wolfgang von Zweibrücken und Neuburg. In: Neuburger Kollektaneenblatt 133 (1980), S. 141-186; Ders.: Scholae Lauingae. Johannes Sturm, das Gymnasium in Lauingen und die Jesuiten in Dillingen. In: Arnold (Hg.): Johannes Sturm (1507-1589), S. 261-292.

61 Zur gleichen Feststellung kommt Pietrzyk im Fall der polnisch-litauischen Republik. Hier gab es neben dem Gymnasium von Lewartów (1580) oder Kryłów (1593) mehr als ein Dutzend von dissidentischen Schulen in Kleinpolen und Ruthenien, die auf den Leitsätzen der „Scholae Lauinganae“ Johannes Sturms fußten. Vgl. Pietrzyk: Die Ausstrahlung Straßburgs im Zeitalter des Humanismus, S. 234, 239.

62 In Schreiben stand als Begründung: „Weilen [...] dieser Orten an Gelehrten und zu dem Ministerio und Schulregiment tauglichen Personen ein großer Mangel sich befinden thut, dann wir mitten unter den Feinden sitzen, und vor dieser Zeit stündlich die Verfolgung zu gewarten gehabt [...]." Zit. nach Johann Samuel Klein: Nachrichten von den Lebensumständen und Schriften Evangelischer Prediger in allen Gemeinden des Königreichs Ungarn. 2 Bde. Leipzig-Ofen 1789, hier Bd. 1, S. 37.

63 Vgl. dazu den Brief der Pressburger vom 2. August 1606. Ebenda. 
64 David Kilger (1572-?) wurde in Burgerschwey in Neuburg geboren, absolvierte ein Universitätsstudium und erwarb den akademischen Grad eines Magisters. Am fürstlichen Gymnasium zu Lauingen war er bis 1605 als Klassenlehrer für die Quarta, also die unterste Gymnasialklasse, dann als Professor der Secunda tätig, bevor er im Sommer 1606 die Einladung nach Pressburg annahm. Vgl. dazu Gernot Ludwig: Zur Geschichte der Fürstlichen Schule des "Gymnasiums illustre“ in Lauingen. Teil XVII. In: Jahresbericht des Albertus-Gymnasiums. Lauingen 1981, S. 76-83.

65 Sámuel Markusovszky: A pozsonyi ág. hit. evang. lyceum története kapcsolatban a pozsonyi ág. hitv. evang. egyház múltjával [Geschichte des Pressburger evangelischen Lyzeums A. B. im Zusammenhang mit der Geschichte der Pressburger evangelischen Kirche A. B.]. Pozsony 1896, S. 7. Vgl. auch die Erwähnung der Entsendung bei Jacob Heilbrunner: Zwo christliche Leichpredigten [...]. Lauingen 1614, Teil II.

66 Zit. nach Markusovszky: A pozsonyi ág. hit. evang. lyceum története, S. 12f.

67 Adam Tettelbach (1580-1613) wuchs bei seinem Großvater, dem Superintendenten Johann Tettelbach, in Burglengenfeld auf, studierte mit einem herzöglichen Stipendium in Wittenberg, wo er am 7. April 1606 den Magistergrad erhielt. In Pressburg war er bis zu seinem Tod am 28. August 1613 tätig. Die Grabrede hielt Pfarrer Simon Heuchlin, die 1614 in Lauingen unter dem Titel „Gedächtnus Predigt Bey der Leichbegängnus deß weyland Ehrwürdigen und wolgelehrten Herrn M. Adam Tettelbachs seliger, geweßnen Evangelischen Predigers in der Königlichen Freystat Preßpurg in Ungern, Welcher den 28. Augusti im Jar Christi 1613. [...] verschieden [...] Sampt etlichen zu End gesetzten Epicediis“" erschien.

68 Als am 13. November 1607 Reuß auf Druck der Pressburger Katholiken vom Stadtmagistrat Predigtverbot erhielt und 1608 die Stadt verließ, wurde Magister Simon Heuchelin aus Lauingen auf Befehl des Herzogs nach Pressburg geschickt. Heuchelin studierte in Tübingen und wirkte seit 1603 als Pfarrer in Strass. In Pressburg wurde er anstelle von Reuß zum ersten Pfarrer der lutherischen Gemeinde berufen, wo er bis zu seinem Tod 1621 wirkte. Vgl. dazu Sámuel Markusovszky: A pozsonyi ág. hitv. ev. egyházközség története [Die Geschichte der Pressburger evangelischen Kirchengemeinde A. B.]. 2 Bde. Pozsony 1906, hier Bd. 2, S. 37f., 65; Maximilian Weigel - Joseph Wopper - Hans Ammon: Neuburgisches Pfarrerbuch. Kallmünz 1967, S. 59.

69 Ebenda, S. 199.

70 Markusovszky: A pozsonyi ág. hit. evang. lyceum története, S. 64-75.

71 Die Forschung hat sich mit dem Aufbau und der Entwicklung dieser Schule im 17. Jahrhundert seit den Arbeiten von Sámuel Markusovszky kaum beschäftigt. Auch die Geschichte der Beziehung zwischen Pressburg und Pfalz-Neuburg ist bis heute unbearbeitet. Eine systematische Untersuchung wäre schon deshalb lohnenswert, weil bereits aus den Informationen in den gedruckten Schriften eine intensive Beziehung zwischen der königlichen Freistadt Pressburg und dem Fürstentum Pfalz-Neuburg in der ersten Hälfte des 16. Jahrhunderts herauszulesen ist.

72 Gerhard Menk: Die Hohe Schule Herborn in ihrer Frühzeit (1584-1660). Ein Beitrag zum Hochschulwesen des deutschen Kalvinismus im Zeitalter der Gegenreformation (= Veröffentlichungen der Historischen Kommission für Nassau XXX). Wiesbaden 1981, S. 27; Ders.: Kalvinismus und Pädagogik. Matthias Martinius (1572-1630) und der Einfluß der Hohen Schule Herborn auf Johann Amos Comenius, in: Nassauische Annalen 91 (1980), S. 77-104; Ders.: Das Restitutionsedikt und die kalvinistische Wissenschaft. Die Berufung Johann Heinrich Alsteds, Philipp Ludwig Piscators und Johann Heinrich Bisterfelds nach Siebenbürgen. In: Jahrbuch der hessischen kirchengeschichtlichen Vereinigung 31 (1980), S. 29-63; Ders.: Territorialstaat und Schulwesen in der frühen Neuzeit. Eine Untersuchung zur religiösen Dynamik an den Grafschaften Nassau und Sayn. In: Jahrbuch für westdeutsche Lan- 
desgeschichte 9 (1983), S. 177-220; Ders.: Die Hohe Schule Herborn, der deutsche Kalvinismus und die westliche Welt. In: Jahrbuch der hessischen kirchengeschichtlichen Vereinigung 35 (1984), S. 351-369; Ders.: Die kalvinistischen Hochschulen und ihre Städte im konfessionellen Zeitalter. In: Heinz Duchhardt (Hg.): Stadt und Universität. Köln 1993, S. 83-106.

73 Remig Békefi: A sárospataki ev. ref. fóiskola 1621-iki törvényei [Die Gesetze der Sárospataker reformierten Hochschule von 1621]. Budapest 1899, S. 198-200; Imre Szentimrei: A sárospataki Református Kollégium 1618-as rendszabályai és 1620-as törvényei [Die Schulordnung von 1618 und die Schulgesetze von 1620 des Sárospataker Reformierten Kollegiums]. Sárospatak 1996, S. 119.

74 Andreas Mühling: „Ein garten junger Pflänzlein“: Ein Herborner Konzept zur Elitenbildung in europäischer Perspektive. In: Herman J. Selderhuis - Markus Wriedt (Hg.): Konfession, Migration und Elitenbildung. Studien zur Theologieausbildung des 16. Jahrhunderts (= Brill's Series in Chruch History 31). Leiden-Boston 2007, S. 311-320.

75 Menk: Die Hohe Schule, S. 306-311.

76 József Koncz: A marosvásárhelyi Evang. Reform. Kollégium története (1557-1895) [Die Geschichte des Reformierten Kollegiums von Marosvásárhely (1557-1895)]. ND Marosvásáhely 2006, S. 478f.

77 Ebenda, S. 480; Károly Szabó: A gyulafehérvári Bethlen-féle fótanoda szervezeti szabályzata [Die Gesetze der Bethlen-Hochschule in Gyulafehérvár]. In: Történelmi Tár 1879, S. 797-805; József Koncz: A fehérvári főiskola történetéhez [Zur Geschichte der Hochschule von Weißenburg]. In: Történelmi Tár 1884, S. 199-201; Ferenc Váró: Bethlen Gábor kollégiuma [Das Kollegium Gábor Bethlens]. Nagyenyed 1903, S. 108-114.

78 Bis Ende des 16. Jahrhunderts waren es etwa 1200 Personen, darunter auch zahlreiche reformierte Studenten. Vgl. dazu Ágnes Ritoókné Szalay: Miért Melanchthon? [Warum Melanchthon?]. In: Mihály Balázs u. a. (Hg.): Müvelödési törekvések a korai újkorban. Tanulmányok Keserü Bálint tiszteletére. Szeged 1997, S. 497-505, S. 498.

79 Wilfried Barner: Barockrhetorik. Untersuchungen zu ihren geschichtlichen Grundlagen. 2. Aufl. Tübingen 2002, S. 257. 